\title{
Uveal melanoma: updated considerations on current management modalities
}

\author{
Willem A. Manschot ${ }^{1}$, William R. Lee ${ }^{2}$ \& Roel van Strik ${ }^{3}$ \\ ${ }^{1}$ Institute of Pathology; ${ }^{3}$ Institute of Epidemiology and Biostatistics, Erasmus University, Rotterdam, \\ The Netherlands; ${ }^{2}$ Departments of Ophthalmology and Pathology, University of Glasgow, Glasgow, Scotland
}

Accepted 30 November 1995

Key words: uveal melanoma, doubling times, first dissemination, irradiation, long term visual acuity, post-therapeutic quality of life

\begin{abstract}
Published data on growth rates of uveal melanomas and effects of treatment modalities raise important considerations. Dissemination from uveal melanomas starts after the tumour is larger than $7 \mathrm{~mm}$ diameter; growth from 7 to $10 \mathrm{~mm}$ diameter increases the risk of metastases incrementally to approximately $16 \%$. Estimations of tumour doubling times indicate that metastatic death before 8 years is nearly always due to pre-therapeutic dissemination so that the impact on survival by therapy can only be assessed thereafter. Histopathology on irradiated melanomas reveals that reproductive activity has not been suppressed and the anticipated (and unfavourable) risk of metastases is not balanced by poor post-irradiation visual acuity. Also the psychological well-being of a patient with a functional fellow eye is better after primary enucleation. Conservative management is most appropriate for: small melanomas, patients with a short life expectancy, melanomas in a single functioning eye, and patients refusing enucleation.
\end{abstract}

Optimum treatment of any form of neoplastic disease by modern therapeutic modalities should ideally be based on an accurate knowledge of the biological behaviour of the specific neoplastic process. With regard to ocular melanomas, there are serious gaps in knowledge concerning growth rates in situ and in the documentation of the time intervals between the presentation of the primary tumour and the appearance of metastases. The rarity of the tumour necessitates careful accumulation of data, so that an adequate analysis can be made of the claimed success of cure rates. Equally important, the side effects and the complications of treatment should be the subject of careful scrutiny. In this communication the literature on the relevant aspects of melanoma biology and current treatment modalities is critically analysed.

\section{Tumour biology}

\section{Tumour doubling time}

Information on tumour doubling time of uveal melanomas was introduced in 1980 [1] and updated reviews were provided in 1987 [2] and in 1992 [3]. From this data it was possible to estimate the risk of metastatic disease in relation to the dimensions of the tumour. The application of meta analysis provided by Diener-West and associates [4] and Markowitz et al. [5] has indicated that a radical reappraisal of the current philosophy of management is required.

\section{When do uveal melanomas metastasize?}

In 1984, an editorial in the American Journal of Ophthalmology stated that it is unclear at what stage in its course a uveal melanoma develops the capacity to metastasize' [6]. However an analysis of the data then available in the literature provided evidence which indicated that metastatic disease does not occur until 
Table 1. Metastatic death after enucleation small melanomas. Davidorf et al. [8].

\begin{tabular}{llcc}
\hline Diameter & $<10 \mathrm{~mm}$ & $<7 \mathrm{~mm}$ & $7-10 \mathrm{~mm}$ \\
\hline Number cases & 50 & 18 & 32 \\
Number 10 yr follow-up & $18+3$ tumour death & $?$ & $?$ \\
Lost to follow-up & 29 & $?$ & $?$ \\
Tumour-related death & $5(10 \%)$ & 0 & $5(16 \%)$ \\
\hline
\end{tabular}

the tumour dimensions are greater than a diameter of 6-7 mm [7]. This conclusion was based on two separate studies of survival from small melanomas treated by enucleation $[8,9]$. In both series $[8,9]$, metastatic death had not occurred in the $<7 \mathrm{~mm}$ diameter groups, but had occurred in $10 \%$ [8] and $9 \%$ [9] in the $<10$ mm diameter groups; it is noteworthy that the $<10 \mathrm{~mm}$ group also included the $<7 \mathrm{~mm}$ cases. Recalculation of this data $[8,9]$ revealed that the percentage metastatic death rate in the group tumours measuring $7-10 \mathrm{~mm}$ in diameter groups appeared to be $16 \%$ and $26 \%$, against zero in the $<7 \mathrm{~mm}$ diameter groups (Tables 1,2 ). There are exceptions, however: one patient with a melanoma $<7 \mathrm{~mm}$ had metastases, but had not yet died. In the literature thereafter, only one more case of metastatic death after enucleation in a patient with $a<7 \mathrm{~mm}$ melanoma has been reported [10]. This data strongly suggests that choroidal melanomas rarely metastasize when the tumours have a diameter less than 6-7 mm at the time of detection.

\section{Death rates in patients with melanomas less than $10 \mathrm{~mm}$ diameter}

The previously cited editorial [6] also stated that patients with melanomas $<10 \mathrm{~mm}$ diameter had 'an excellent prognosis regardless of treatment; the fiveyear tumour-related mortality in this group is less than $5 \%$ '. This statement, clearly contradicted by the observation shown in Tables 1 and 2, can be seriously challenged by the application of meta-analysis, which provides proof that five-year mortality rate in patients with melanomas < $10 \mathrm{~mm}$ diameter is $16 \%$ [4]. This implies that prolonged clinical observation of melanomas as they enlarge from $7 \mathrm{~mm}$ diameter to $10 \mathrm{~mm}$ diameter could result in the death of $16 \%$ of these patients. However it is too simplistic to suggest that all such patients with small pigmented tumours of $6-7 \mathrm{~mm}$ or less should be treated by immediate enucleation since many such tumours could be nævi and the majority of melanomas are not brought to the attention of ophthalmologists at this stage. Nonetheless on theoretical grounds, metastatic death could have been averted by complete eradication of the malignant neoplasm at the 6-7 mm stage and this important postulate should not be neglected.

\section{Failure to appreciate the consequences of 'doubling time'}

The new approach to uveal melanomas, published in 1980 [1], with regard to their biological behaviour, was based on the published data on skin melanomas, for which tumour doubling times (Td's) had been calculated. Information derived from this literature showed that the time intervals between dissemination and metastatic death were widely spread and varied between 3 and 30 years.

Subsequently numerous reports on tumour doubling times in uveal melanomas have been provided [11-14]; in only three out of thirty-nine patients were the doubling times estimated to be shorter than 60 days.

On theoretical grounds it has been suggested that metastatic tumour death (after the primary tumour has released cells into the circulation) will occur at a time interval derived from multiplication of the tumour doubling time by $35-40$ [15]. This postulate (which does not assume that all metastases grow exponentially from the first cell division to a clinically detectable size, because the tumour doubling time represents a mean value) has not been contradicted in later studies [see reference 3], which have repeated and extended the fundamental work of Collins [15].

Taking these two assumptions together, it may, therefore, be accepted for practical therapeutic and prognostic considerations in individual patients, that death from metastatic death in unlikely to occur before $35 \times 60$ days or no less than six years after dissemination of the first viable embolus of tumour cells.

Furthermore, since the tumour doubling times of uveal melanomas may exceed 200 days, the time interval between dissemination and metastatic death may vary widely and range from 6 to 60 years. Crowley [16] reported a mean disease-free interval for cutaneous 
Table 2. Metastatic death after enucleation small melanomas. Thomas et al. [9].

\begin{tabular}{llcc}
\hline Diameter & $<10 \mathrm{~mm}$ & $<7 \mathrm{~mm}$ & $7-10 \mathrm{~mm}$ \\
\hline Number cases & 65 & 42 & 23 \\
Number 10 yr follow-up & $27(0$ tumour death $)$ & $?$ & $?$ \\
Lost to follow-up & 38 & $?$ & $?$ \\
Tumour-related death & $6(9 \%)$ & 0 & $6(26 \%)$ \\
\hline
\end{tabular}

melanomas of 14.3 years and compared this with 22.3 years for primary ocular lesions. It is noteworthy that in this series [16], five out of twelve ocular melanoma patients had a tumour-free interval of $47,45,30,28$ and 27 years, respectively.

The minimal latent interval of six years implies that metastatic death within 7-8 years after local therapy on the uveal melanoma is nearly always due to pretherapeutic dissemination. This is the only reason why a statistically significant impact on survival has never been and never will be established by a detailed analytical comparison of survival rates within 8-10 years after various conservative interventions, after primary enucleation or after observation only. It is therefore more likely that differences in survival rates after any given form of treatment will reflect the selection criteria for patients subjected to that specific form of treatment. The validity of this postulate is supported by the agreement in all reports, that within the first 8-10 years no significant difference in survival rate has ever been noted when various treatment modalities are compared [17-21] or when survival in 'promptly treated patients' is compared with those in whom 'treatment has been delayed' [22].

Therefore, the essential requirements for valid statistical comparisons are:

- a 10-15 year survival rate of all treated patients, and

- accurate assessment of visual function in all living patients after a 5-year or more follow- up, without any selection bias.

Many ophthalmic oncology institutes have employed conservative management in uveal melanomas for 1520 years, but rather surprisingly, results after followup periods of 10 years or more of all treated patients have not been made available. Neglect in providing this fundamental information has been highlighted by Markowitz et al. [5], who emphasized that researchers, clinicians, journal editors, and reviewers should be more attentive to the completeness of reports from clinical research studies; attention to basic information regarding design and methods was strongly recommended. Statements made by these authors [5] con- cerning the overall quality of reporting (which have not improved over the last two decades) should not be ignored. Publication of unverifiable data still continues e.g. visual acuities between $6 / 24$ and zero are unspecified, and statements such as 'stable disease', defined as 'an elevated remnant, remaining unchanged for at least one year' are equally vague [23].

\section{Tumour biology in relation to ionising radiation}

A consideration of the histopathological findings in 231 eyes containing irradiated melanomas was provided in 1992 [3]. Thereafter, another 170 such pathological studies have been reported [24-31]. A substantial number of irradiated tumours are treated successfully, but the actual percentage of loss of proliferative capacity of all stem cells will never be known. To compound the difficulty in assessment, a sufficient follow-up period for all irradiated patients may never be achieved and by the very nature of the treatment, radiotherapy is applied to 'masses' which are not histologically classified.

The well-established radio-insensitivity of uveal melanomas is reflected in the absence of radiationinduced necrosis in about $40 \%$ of the treated tumours, and in the identification of well-preserved tumour cells in about $95 \%$ of the specimens [3]. Appearances suggesting continuing tumour cell activity was noted in ruthenium ${ }^{106}$-irradiated melanomas in 55 of 56 cases [24]. On the other hand, microscopically complete tumour necrosis was found in 10 out of 25 large melanomas, measuring $>7-8 \mathrm{~mm}$ in height after iodine ${ }^{125}$-brachytherapy [25]. In another report unequivocal mitoses were found in $36 \%$ of tumours, treated with various types of radioactive plaques: enucleation was performed at an average of 29 months after therapy [26]. Mitoses were also reported in $20 \%$ of 25 ruthenium ${ }^{106}$-treated melanomas [27]. Mitoses after proton beam irradiation have been described in $9(27 \%)$ of 33 melanomas [28]. Similar data was obtained from five proton beam-treated tumours in five patients [29] and in four of seven cases [30]. The two latter reports 
Table 3. Reported visual acuities (VA) or adverse visual events (AVE)*.

\begin{tabular}{|c|c|c|c|}
\hline & No. & Follow-up & VA or AVE \\
\hline Lommatzsch $(1986)^{a} 33$ & 227 & 5 years & $\begin{array}{l}\text { First VA }>0.3: 31(14 \%)^{3} \\
\text { Last VA }<0.2: 83(37 \%)^{3}\end{array}$ \\
\hline Tjho-Heslinga $(1993)^{a} 23$ & 49 & $1-6$ years & $\begin{array}{l}\text { First VA } \leq 0.25: 9(19 \%) \\
\text { Last VA } \leq 0.25: 19(39 \%)\end{array}$ \\
\hline Linstadt $(1988)^{b 34}$ & 189 & $\begin{array}{l}\text { median } \\
26 \text { months }\end{array}$ & $\begin{array}{l}\text { First VA } \geq 0.1: 164(87 \%) \\
\text { Last VA } \geq 0.1: 89(48 \%)\end{array}$ \\
\hline Kindy-Degnan $(1989)^{b 35}$ & 279 & 3 years & $\begin{array}{l}\text { First VA } \geq 0.5: 173(62 \%) \\
\text { Last } V A \geq 0.5: 27(10 \%) \\
\text { First } V A>0.1: 238(85.3 \%) \\
\text { Last } V A>0.1: 35(12.5 \%)\end{array}$ \\
\hline Char $(1993)^{b 36}$ & 86 & $4-5$ years & $\begin{array}{l}\text { First VA } \geq 0.5: 26(30 \%) \\
\text { Last VA } \geq 0.5: 16(19 \%) \\
\text { First VA } \leq 0.1: 6(7 \%) \\
\text { Last VA } \leq 0.1: 58(67.4 \%)\end{array}$ \\
\hline Char $(1993)^{c 36}$ & 98 & $4-5$ years & $\begin{array}{l}\text { First VA } \geq 0.5: 29(29 \%) \\
\text { Last VA } \geq 0.5: 23(23.5 \%) \\
\text { First VA } \leq 0.1: 9(9.2 \%) \\
\text { Last } V A \leq 0.1: 66(67 \%)\end{array}$ \\
\hline Packer $(1992)^{c} 37$ & 63 & $\begin{array}{l}\text { mean } \\
65 \text { months }\end{array}$ & $\begin{array}{l}\text { Total AVE: } 49(77.8 \%) \\
\text { Last VA } \leq 0.1: 35(55 \%)\end{array}$ \\
\hline Fontanesi $(1993)^{c 38}$ & 144 & $\begin{array}{l}\text { median } \\
46 \text { months }\end{array}$ & $\begin{array}{l}\text { First VA }<0.1: 29 \%^{3} \\
\text { Last VA }<0.1: 59 \%^{3}\end{array}$ \\
\hline Guyer $(1992)^{d} 39$ & 218 & $\begin{array}{l}\text { mean } \\
40 \text { months }\end{array}$ & $\begin{array}{l}\text { First VA }<0.1: 22(10 \%)^{3} \\
\text { Last VA }<0.1: 86(39.4 \%)^{3}\end{array}$ \\
\hline
\end{tabular}

${ }^{a}$ Ruthenium ${ }^{106} ;^{b}$ Helium ions; ${ }^{c}$ Iodine ${ }^{125} ;^{d}$ Proton beam. * Adverse visual event: acuity decreased to $\leq 6 / 30$ or $\geq 2$ lines. ${ }^{3}$ Data unverifiable or concerning selected groups of patients.

noted intervals between irradiation and enucleation of 36,49 and 66 months. Mitoses in a growing tumour and mitoses of more than two years after irradiation must be regarded as significant indicators of the presence of viable tumour stem cells. Their presence indicates a failure of irradiation to abolish the proliferative capacity of the stem cells within the tumour.

\section{Clinical implications}

The importance of long-term visual acuity data

Preservation of vision is the principle justification for conservative management of ocular melanomas. It is unfortunate therefore, that some of the radiotherapeutic and surgical centres which publish regularly, have been reluctant to present verifiable, detailed data on the retained visual acuity of all treated patients. In general, follow-up periods of visual function have been shorter than those for other data relevant to the treatment and further management of the patients. An extreme example of a great potential for bias is presented in a report [32] published in 1993, on 163 patients who had been treated between 1972 and 1991. This study mentions only a 'one-year (!) post-operatively retained visual acuity of all patients'. Moreover, vision had been measured with a pinhole aperture. The reported visual acuity is, therefore, in no sense representative of the post-therapeutic quality of life of these patients.

An appropriate method of analysing the published accounts of post-therapeutic visual function would be to arrange the data according to various irradiation modalitis (Table 3 ).

The lack of uniformity in the published information prevented the use of one scale in this table, so that proper comparisons could not be made and the data not added. It would be highly desirable if the Collaborative Ocular Melanoma Study (COMS) and those large centres, which do not participate in the COMS, could reach an agreement to use identical designs and methods for their future follow-up reports. This would 
enable an appropriate long-term appraisal of the data for retention of useful visual function, particularly with reference to different treatment modalities.

It may be noted that some numbers and percentages in Table 3 do not correspond with the data provided in the original reports. Several authors used percentages which did not refer to all treated patients, but to selected sub-groups. As far as possible, the recalculated data in Table 3 refer to all treated patients. The information provided confirms that visual acuity has decreased to $<6 / 60$ in about $50 \%$ of the eyes, three years after irradiation using any modality. A continuing decrease in visual acuity of about $10 \%$ per annum has also been noted [40]. A randomized study [36] to compare the results of helium ion irradiation versus $\mathbf{I}^{125}$-brachytherapy showed that visual acuity had decreased by $\geq 4$ lines in $69 \%$ of each group. Another study on visual acuity after $\mathbf{I}^{125}$-therapy [37] revealed that $49(78 \%)$ of 63 patients had an acuity decreased to $\leq 6 / 30$, or an acuity which had decreased 2 lines or more. It was concluded that the eye encounters significant morbidity after $\mathrm{I}^{125}$-irradiation. Data on posttherapeutic visual acuity after ruthenium ${ }^{106}$, cobalt $^{60}$ and proton beam irradiation have either not been published, or have been reported in an incomplete fashion, with short follow-up periods, which prevent comparison with other therapeutic modalities.

After five years, some $70 \%$ or more of irradiated eyes in which data were verifiable had retained a visual acuity of $\leq 6 / 60$ (Table 3 ). A case report [41] mentions a maintained reading vision 10 years after proton beam irradiation of a histologically proven macular melanoma. The generally poor visual result however questions the authenticity of the 'fight for sight' justification for conservative treatment. The anticipated incremental ratio of the 'unfavourable risk' of posttherapeutic dissemination from retained viable tumour stem cells against the 'benefit' of the conservative procedure cannot be assessed before ten post-therapeutic years, due to our inability to control metastatic disease.

\section{The future quality of life after treatment}

There is little consideration in the literature on conservative management of the post-therapeutic physical and psychological stresses imposed on the treated patients. Considerable anxiety arises from frequent reexamination, re-treatment of recurrence, and the treatment of the complications after irradiation $[29,30,37$, 42,43 ] or intraocular surgery [32]. This contrasts with patients treated by primary enucleation, who, more- over, are unaware of the anxious and depressing burden of harbouring an intraocular malignancy, which might continually have the capacity to disseminate and to cause a much feared metastatic death.

By contrast, the impact of enucleation on the postsurgical quality of life has not been found to be significant in four vision-dependent activities: viz. working; driving, reading and television viewing in $62(87 \%)$ of 71 patients [44]. Fifteen years after enucleation, 18/20 $(90 \%)$ of patients retained the ability to drive and $25 / 26$ $(96 \%)$ retained the ability to read. Another comparative study on the same four post-enucleation visiondependent activities as against those of brachytherapy [45] revealed that $48 / 51(94 \%)$ of the patients after enucleation and 46/51 (90\%) of those after irradiation - mean follow-up of respectively 89 and 87 months - reported no vision-related change in any of these four activities. It appears questionable, therefore, to burden a patient with a normally functioning felloweye with the incremental risk of preventable metastatic death by post-therapeutic dissemination from a uveal melanoma.

An examplary 25-35 year follow-up report [46] on 302 between $1943-1952$ primary enucleated patients with a posterior uveal melanoma, with a follow-up percentage of $99.8 \%$, revealed that $148(49 \%)$ patients had been saved from metastatic death. In the intervening decades the figure of $40 \%$ should, in theory, have been markedly improved. Present diagnostic techniques provide earlier detection rates in small melanomas and survival rates after enucleation depend largely on the volume of the tumour at the time of enucleation. Knowledge that a malignancy has been removed completely is the predominant factor in the future psychological well being of many patients.

\section{References}

1. Manschot WA, Van Peperzeel HA. Choroidal melanoma. Enucleation or observation? A new approach. Arch Ophthalmol 1980; 98: 71-7.

2. Manschot WA, van Strik R. Is irradiation a justifiable treatment of choroidal melanoma? Analysis of published results. $\mathrm{Br} \mathbf{J}$ Ophthalmol 1987; 71: 348-52.

3. Manschot WA, van Strik R. Uveal melanoma: therapeutic consequences of doubling times and irradiation results: a review. Int Ophthalmol 1992; 16: 91-9.

4. Diener-West M, Hawkins BS, Markowitz JA, Schachat AP. A review of mortality from choroidal melanoma. II. A metaanalysis of 5-year mortality rates following enucleation, 1966 through 1988. Arch Ophthalmol 1992; 110: 245-50.

5. Markowitz JA, Hawkins BS, Diener-West M, Schachat AP. A review of mortality from choroidal melanoma. I. Quality of 
published reports, 1966 through 1988. Arch Ophthalmol 1992; 110: $239-44$.

6. Char DH. Therapeutic options in uveal melanoma. Am J Ophthalmol 1984; 98: 796-9.

7. Manschot WA. Therapeutic options in uveal melanoma. Correspondence. Am J Ophthalmol 1985; 99: 615-6.

8. Davidorf $\mathrm{FH}$, Lang JR. The natural history of malignant melanoma of the choroid: small vs large tumors. Trans Am Acad Ophthalmol and Otolaryngol 1975; 79: 310-20.

9. Thomas JV, Green R, Maumenee AE. Small choroidal melanomas. A long term follow-up study. Arch Ophthalmol 1979; 97: 861-4.

10. Barr CC, Sipperly JO, Nicholson DH. Small melanomas of the choroid. Arch Ophthalmol 1978; 96: 1580-2.

11. Friberg TR, Fineberg E, McQuaig S. Extremely rapid growth of a primary choroidal melanoma. Arch Ophthalmol 1983; 101: $1375-7$.

12. Augsburger JJ, Gonder JR, Amsel J, Shields JA, Donoso LA. Growth rates and doubling times of posterior uveal melanomas. Ophthalmology 1984; 91: 1709-15.

13. Gass JDM. Comparison of uveal melanoma growth rates with mitotic index and mortality. Arch Ophthalmol 1985; 103:92431.

14. Sahel JA, Pesavento R, Frederick AR, Albert DM. Melanoma arising de novo over a 16 month period. Arch Ophthalmol $1988 ; 106: 381-5$.

15. Collins VP, Loeffler RK, Tivey H. Observations on growth rates of human tumors. Am J Radiol 1956; 76: 988-1000.

16. Crowley NJ, Seigler HF. Late recurrence of malignant melanoma. Analysis of 168 patients. Ann Surg 1990; 212: 173-7.

17. Augsburger JJ, Gamel JW, Lauritzen K, Brady LW, Cobalt60 plaque radio-therapy vs enucleation for posterior uveal melanoma. Am J Opthalmol 1990; 109: 585-92.

18. Char DH, Quivey JH, Castro JR, Kroll S, Phillips T. Helium ions versus iodine-125 brachytherapy in the management of uveal melanoma. Ophthalmology 1990; 100: 1547-54.

19. Seddon JM, Gragoudas ES, Egan KM, Glynn RJ, Fante HS, Albert DM. Relative survival rates after alternative therapies for uveal melanoma. Ophthalmology 1990; 97: 769-77.

20. Gragoudas ES, Seddon JM, Egan K. Proton beam irradiation of intraocular melanomas. Results in 10 years after treatment. Meeting Club Jules Gonin, Vienna, Austria, 1992; Sept 6-10: 9.

21. Guthoff R, Frischmuth J, Jensen OA, Bjerrum K, Prause JU. Das Aderhautmelanom. Eine retrospektive randomisierte Vergleichsstudie Ruthenium Bestrahlung vs Enukleation. Klin Mbl Augenheilk 1992; 200: 257-61.

22. Augsburger JJ, Vrabec TR. Impact of delayed treatment in growing posterior uveal melanomas. Arch Ophthalmol 1993; 111: 1382-6.

23. Tjho-Heslinga RE, Kakebeeke-Kemme HM, Davelaar J, de Vrome H, Bleeker JC et al. Results of ruthenium irradiation of uveal melanoma. Radiother Oncol 1993; 29: 33-8.

24. Messmer EP, Bornfeld N, Foerster M, Schilling H, Wessing A. Histopathologic findings in eyes treated with a ruthenium plaque for uveal melanoma. Graefe's Arch Clin Exp Ophthalmol 1992; 230: 391-6.

25. Schilling H, Bornfeld N, Friedrichs W, Pauleikhoff D, Sauerwein W, Wessing A. Histopathologic findings in large uveal melanomas after brachytherapy with iodine 125 plaques. German J Ophthalmol 1994; 3: 232-8.

26. Shields CL, Shields JA, Karlson U, Menduke H, Brady LW. Enucleation after plaque radiotherapy for posterior uveal melanoma. Histopathologic findings. Ophthalmology 1990 97: 1665-9.

27. Klaus H, Lommatzsch PK, Fuchs U. Histopathology studies in human malignant melanomas of the choroid after unsuccessful treatment with ${ }^{106} \mathrm{Ru} /{ }^{106} \mathrm{Rh}$ ophthalmic applicators. Graefe's Arch Clin Exp Ophthalmol 1991; 229: 480-6.

28. Saornil MA, Egan KM, Gragoudas ES, Seddon JM, Qualsh SM, Albert DM. Histopathology of proton beam-irradiated vs enucleated uveal melanomas. Arch Ophthalmol 1992; 110: $1112-8$.

29. Kincaid MC, Folberg R, Torczinsky E, Zakov ZN, Shore JW et al. Complications after proton beam therapy for uveal malignant melanoma. Ophthalmology 1988; 95: 982-91.

30. Liszauer AD, Brownstein S, Corriveau C, Deschenes J. A clinicopathological study of seven globes enucleated after primary radiation therapy for malignant melanoma of the choroid or ciliary body. Can J Ophthalmol 1990; 25: 340-4.

31. Petrovich Z, McDonnell JM, Palmer D, Langholz BM, Liggett PE. Histopathologic changes following irradiation for uveal tract melanoma. Am J Clin Oncol 1994; 17: 298-306.

32. Damato BE, Paul J, Foulds WS. Predictive factors of visual outcome after local resection of choroidal melanoma. $\mathrm{Br} \mathrm{J}$ Ophthalmol 1993; 77: 616-23.

33. Lommatzsch PK. Results after $\beta$-irradiation $\left({ }^{106} \mathrm{Ru} /{ }^{106} \mathrm{Rh}\right)$ of choroidal melanomas: 20 years' experience. Br J Ophthalmol 1986; 70: 844-51.

34. Linstadt D, Char DH, Castro JR, Phillips TL, Quivey JM, Reimers $\mathrm{M}$ et al. Vision following helium ion radiotherapy of uveal melanomas: a Northern California oncology group study. Int J Rad Oncol Biol Phys 1988; 15: 347-52.

35. Kindy-Degnan NA, Char DH, Castro JR, Kroll S, Stone RD, Quivey JM, Reimers M et al. Effects of various doses of radiation for uveal melanoma on regression, visual acuity, complications and survival. Am J Ophthalmol 1989; 107: 114-22.

36. Char DH, Quivey JM, Castro JR, Kroll S, Phillips T. Helium ions vs iodine 125 brachytherapy in the management of uveal melanoma. Ophthalmology 1993; 100: 1547-54.

37. Packer S, Stoller S, Lesser ML, Mandel FS, Finger PT. Longterm results of iodine 125 irradiation of uveal melanoma. Ophthalmology 1992; 99: 767-74.

38. Fontanesi J, Meyer D, Xu S, Tai D. Treatment of choroidal melanoma with I-125 plaque. Int J Rad Oncol Biol Phys 1993; 26: 619-23.

39. Guyer DR, Mukai S, Egan KM, Seddon JM, Walsh SM, Gragoudas ES. Radiation maculopathy after proton beam irradiation for choroidal melanoma. Ophthalmology 1992; 99 : 1278-85.

40. Brady LW, Markoe AM, Amendola BE, Karlsson UL, Micaily B, Shields JA, Augsburger JJ. The treatment of primary ocular malignancy. Int J Rad Oncol Biol Phys 1988; 15: 1355-61.

41. Young LHY, Gragoudas ES. Macular uveal melanoma treated with proton beam irradiation: 10-year follow-up observation with histopathologic correlation. Retina 1994; 14: 43-6.

42. Meccham WJ, Char DH, Kroll S, Castro JR, Blakeley EA. Anterior segment complications after helium ion radiation therapy for uveal melanoma: radiation cataract. Arch Ophthalmol 1994; 112: 197-203.

43. Gragoudas ES, Egan KH, Walsh SM, Regan S, Munzenrider JE, Taratuta V. Lens changes after proton beam irradiation for uveal melanoma. Am J Ophthalmol 1995; 119: 157-64.

44. Edwards MG, Schachat AR. Impact of enucleation for choroidal melanoma on the performance of vision-dependent activities. Arch Ophthalmol 1991; 109: 519-21. 
45. Augsburger JJ, Goel SD. Visual function following enucleation or episcleral plaque radiotherapy for posterior uveal melanoma. Arch Ophthalmol 1994; 112: 786-8.

46. Jensen OA. Malignant melanomas of the human uvea: 25 -year follow-up of cases in Denmark, 1943-1952. Arch Ophthalmol 1982; 60: 161-82.
Address for correspondence: W.A. Manschot, Institute of Pathology, Erasmus University, P.O. Box 1738, 3000 DR Rotterdam,

The Netherlands 